Arq. Bras. Med. Vet. Zootec., v.63, n.6, p.1479-1486, 2011

\title{
Ácidos graxos voláteis no rúmen de vacas alimentadas com diferentes teores de concentrado na dieta
}

[Volatile fatty acids in rumen of cows fed different concentrate level diets]

\author{
S.R. Goularte ${ }^{1}$, L.C.V. Ítavo ${ }^{2,8}$, G.T. Santos ${ }^{3}$, C.C.B.F. Ítavo ${ }^{4}$, L.C.S. Oliveira $^{5}$, S.P. Favaro ${ }^{2}$, \\ A.M. Dias $^{2}$, R.A.A. Torres Junior ${ }^{6}$, C.M.M. Bittar ${ }^{7}$ \\ ${ }^{1}$ Aluna de pós-graduação - Universidade Católica Dom Bosco - UCDB - Campo Grande, MS - Bolsista FUNDECT \\ ${ }^{2}$ Universidade Católica Dom Bosco - UCDB - Campo Grande, MS \\ ${ }^{3}$ Universidade Estadual de Maringá - UEM - Maringá, PR \\ ${ }^{4}$ Universidade Federal de Mato Grosso do Sul - UFMS - Campo Grande, MS \\ ${ }^{5}$ Universidade Federal da Grande Dourados - UFGD - Dourados, MS \\ ${ }^{6}$ Embrapa Gado de Corte - CNPGC - Campo Grande, MS \\ ${ }^{7}$ Escola Superior de Agricultura "Luiz de Queiroz" - ESALQ - Piracicaba, SP \\ ${ }^{8}$ Bolsista de produtividade $\mathrm{CNPq}$
}

\section{RESUMO}

Avaliou-se o efeito de teores de concentrado na dieta sobre a concentração de ácidos graxos voláteis no líquido ruminal de bovinos. Foram utilizadas quatro vacas mestiças, fistuladas no rúmen, com peso médio de $442,15 \mathrm{~kg}$, distribuídas em quadrado latino $4 \mathrm{x} 4$, divididos em quatro períodos de 14 dias, sendo 11 de adaptação e três para coleta de dados. Foi utilizada a silagem de milho, como volumoso, e milho, sorgo, farelo de soja, casca de soja, ureia e gordura protegida, como concentrado. As dietas foram formuladas para 13\% de proteína bruta (PB), utilizando-se proporções de 30; 40; 50 e $60 \%$ de concentrado. Não houve influência do tratamento para concentrações de ácido acético, isobutírico, butírico, isovalérico e valérico. O ácido propiônico e a proporção acetato:propionato apresentaram concentrações máximas em 8,44 e 8,14 horas após a alimentação, respectivamente. Os ácidos graxos totais não foram influenciados pelos tratamentos, com concentração máxima em 7,68 horas após a alimentação, juntamente com valores mínimos de $\mathrm{pH}$ entre seis e nove horas. Dietas com até $60 \%$ de concentrado na matéria seca total não influenciaram as concentrações de ácidos graxos voláteis do rúmen.

Palavras-chave: bovino, acetato, butirato, gordura protegida, propionato

\begin{abstract}
The influence of concentrate levels from the diet on the content of volatile fatty acids in rumen fluid of cattle was evaluated. Four rumen fistulated crossbred cows, weighting around $442.15 \mathrm{~kg}$, were distributed in 4x4 Latin square schedule, divided into four periods of 14 days, 11 for adaptation and three for data collection. Corn silage was used as roughage, and corn, sorghum, soybean meal, soybean hulls, protected fat and urea, as concentrate. Diets were formulated with $13 \%$ crude protein (CP), using the proportions of 30, 40, 50 and 60\% concentrate. There was no influence of treatment for the following acid concentrations: acetic, isobutyric, butyric, isovaleric and valeric. The propionic acid content and the ratio acetate: propionate showed values of 8.44 and 8.14 hours after feeding, respectively. The total fatty acids were not affected by treatments, with maximum concentration at 7.68 hours after feeding, with minimum $\mathrm{pH}$ values between six and nine hours. Diets containing up to $60 \%$ of concentrate in dry matter did not influence the concentrations of rumen volatile fatty acids.
\end{abstract}

Keywords: cattle, acetate, butyrate, fat by pass, propionate

Recebido em 17 de abril de 2010

Aceito em 2 de setembro de 2011

E-mail: sandra.goularte@gmail.com 


\section{INTRODUÇÃO}

A principal fonte de energia para os ruminantes são os ácidos graxos voláteis (AGV) produzidos no rúmen pela fermentação microbiana de carboidratos e, em alguns casos, da proteína, sendo o acético, propiônico e butírico os principais (Berchielli et al., 2006). As proporções molares de acetato:propionato: butirato são variáveis, sendo encontrados valores de 75:15:10, em dietas ricas em carboidratos fibrosos, até 40:40:20, em dietas ricas em carboidratos não fibrosos (CNF), com o total de $\mathrm{AGV}$ entre 60 e $150 \mathrm{mM} / \mathrm{mL}$ de líquido ruminal, sendo estes ácidos reflexo da atividade microbiana e da absorção através da parede ruminal.

A população microbiana do rúmen geralmente converte os carboidratos fermentados em 60 a $70 \%$ de ácido acético, 18 a 22\% de ácido propiônico, 13 a $16 \%$ de ácido butírico e 2 a $4 \%$ de ácido valérico (Teixeira e Teixeira, 2001), os quais podem prover até $80 \%$ da exigência diária de energia dos ruminantes (Bergman, 1990).

A remoção-absorção dos AGV do rúmen-retículo ocorre por dois processos: absorção passiva, pela parede do órgão, e passagem com a fase fluída para o omaso (Tamminga e Van Vuuren, 1988). Se a taxa de produção excede a de remoção, existe acúmulo de $\mathrm{AGV}$ no rúmen, podendo desencadear distúrbios metabólicos (Barker et al., 1995), com efeitos negativos sobre o desempenho e a saúde dos animais.

A ingestão de alimentos rapidamente fermentescíveis, por exemplo, aumenta a atividade microbiana, causando substancial flutuação nos produtos finais da fermentação (ácidos graxos voláteis e amônia) e no pH ruminal, fato que pode refletir no aproveitamento dos demais nutrientes da dieta (Costa et al., 2008). A quantidade em excesso de concentrado fornecido a animais de alta produção pode acarretar problemas metabólicos e tem sido relacionada com a possível diminuição nas proporções de butirato e acetato ruminal.

A utilização de fontes de gordura representa uma opção para reduzir o desequilíbrio energético, incrementando a densidade energética da dieta e mantendo um balanço mais adequado entre carboidratos fibrosos e não fibrosos (Balieiro-
Neto e Melloti, 2007). A suplementação lipídica também tem sido associada com a redução na população de protozoários (Ivan et al., 2001), o que pode alterar as proporções de $\mathrm{AGV}$, sendo provavelmente um fator promotor de depressão da gordura do leite (Ørskov e Ryle, 1990).

Os suplementos lipídicos insaturados apresentam, em doses elevadas, efeito tóxico sobre as bactérias do rúmen, sobretudo a população celulolítica (Nagaraja et al., 1997), alterando a proporção acetato:propionato, em razão da produção de propionato à custa de acetato, e também da redução da produção de metano e da diminuição da amônia ruminal. Uma das maneiras de diminuir esses efeitos é o uso de gordura na forma protegida, como, por exemplo, ácidos graxos insaturados complexados com cálcio, que não são utilizados pelos microrganismos do rúmen, com aproveitamento intestinal (Jenkins, 1993).

Estudos sobre os pontos de controle da lipólise e da bio-hidrogenação podem promover oportunidades de se descobrir os efeitos positivos e negativos sobre a fermentação microbiana (Ítavo et al., 2005). Dessa forma, este trabalho teve o objetivo de avaliar a produção de ácidos graxos voláteis no rúmen de vacas leiteiras não lactantes, alimentadas com diferentes teores de concentrado na dieta.

\section{MATERIAL E MÉTODOS}

Para o experimento, foram utilizadas quatro vacas leiteiras, mestiças e não lactantes, fistuladas no rúmen, com peso médio de $442,15 \mathrm{~kg}$. As vacas permaneceram estabuladas, em sistema tie stall, com água à vontade e arraçoamento uma vez ao dia, de forma a manter as sobras em torno de $5 \%$ do fornecido, em base de matéria seca.

O ensaio foi dividido em quatro períodos experimentais, de 14 dias, compreendendo 11 dias de adaptação à dieta e três dias de coletas, totalizando 56 dias de ensaio, em quadrado latino 4x4 (quatro tratamentos e quatro períodos). Diariamente, nos períodos de adaptação e de coletas, foram feitas pesagens e amostragens da silagem, do concentrado oferecido e das sobras, sendo amostra composta por animal/período. Após a amostragem, o material foi colocado em sacos plásticos, devidamente identificados e 
congelados a $-15^{\circ} \mathrm{C}$, para posteriores análises bromatológicas segundo Silva e Queiroz (2002).

Os tratamentos consistiram na variação da proporção volumoso:concentrado 70:30; 60:40; 50:50 e 40:60, com base na matéria seca. As dietas foram formuladas com teor de proteína bruta em torno de $13 \%$, utilizando-se ureia pecuária como fonte suplementar de nitrogênio. $\mathrm{O}$ volumoso utilizado foi silagem de milho, e o concentrado foi à base de milho (20\%), sorgo (20\%), farelo de soja (27\%), casca de soja $(20 \%)$, suplemento mineral, ureia $(2 \%)$ e gordura protegida (9\%) (Tab. 1).

Tabela 1. Composição percentual de ingredientes da dieta e teores de matéria seca (MS), matéria orgânica $(\mathrm{MO})$, proteína bruta $(\mathrm{PB})$, extrato etéreo (EE) e fibra em detergente neutro (FDN), em função do teor de concentrado

\begin{tabular}{|c|c|c|c|c|}
\hline \multirow[b]{2}{*}{ Nutriente } & \multicolumn{4}{|c|}{ Concentrado (\%) } \\
\hline & 30 & 40 & 50 & 60 \\
\hline \multicolumn{5}{|c|}{ Composição da dieta (\% MS) } \\
\hline Silagem de milho & 68,69 & 59,36 & 49,71 & 40,08 \\
\hline Concentrado ${ }^{1}$ & 29,67 & 39,54 & 49,74 & 59,82 \\
\hline Ureia & 1,64 & 1,10 & 0,55 & 0,00 \\
\hline \multicolumn{5}{|c|}{ Composição químico-bromatológica ${ }^{2}$} \\
\hline MS (\%) & 51,37 & 56,02 & 60,67 & 65,32 \\
\hline $\mathrm{MO}(\% \mathrm{MS})$ & 95,98 & 96,48 & 96,49 & 98,73 \\
\hline PB (\%MS) & 13,50 & 13,28 & 12,96 & 12,91 \\
\hline $\mathrm{EE}(\% \mathrm{MS})$ & 3,23 & 3,68 & 4,13 & 4,71 \\
\hline FDN (\%MS) & 53,48 & 51,75 & 50,02 & 48,29 \\
\hline
\end{tabular}

${ }^{\mathrm{T}}$ Concentrado: $27 \%$ de farelo de soja ; $20 \%$ de milho grão moído; $20 \%$ de casca de soja; $20 \%$ de sorgo grão moído; $9,0 \%$ de gordura protegida; $2 \%$ de ureia e $2 \%$ de núcleo mineral.

${ }^{2}$ Análises realizadas de acordo com Silva e Queiroz (2002).

No último dia de cada período experimental, foram realizadas coletas de líquido ruminal, visando à determinação do $\mathrm{pH}, \quad \mathrm{N}-\mathrm{NH}_{3}$ e concentrações de ácidos graxos voláteis, com início antes do fornecimento da dieta, tomados como tempo zero e 3, 6, 9 e 12 horas após a alimentação.

O material coletado foi filtrado em camadas de gaze a fim de se obter $100 \mathrm{~mL}$ de líquido ruminal. Imediatamente, foi determinado o $\mathrm{pH}$ em potenciômetro digital e em seguida, adicionado $1 \mathrm{~mL}$ de solução de ácido clorídrico $(\mathrm{HCl})$ 1:1. As amostras foram armazenadas em recipientes plásticos a $-5^{\circ} \mathrm{C}$. A análise de ácidos graxos voláteis foi realizada na Escola Superior de Agricultura Luiz de Queiroz, Piracicaba, SP.

Para determinação de ácidos graxos de cadeia curta (AGCC), as amostras foram centrifugadas a $15.000 \mathrm{~g}\left(4^{\circ} \mathrm{C}\right)$, durante 50 minutos, e em seguida, analisadas em cromatógrafo líquido-gasoso (Hewlett Packard 5890 Series II GC, coluna empacotada cabopack, $3 \mathrm{~m}$ ), com temperatura do forno de $120^{\circ} \mathrm{C}$, equipado com integrador (Hewlett Packard 3396 Series II Integrator) e injetor automático (Hewlett Packard 6890 Series
Injector) à temperatura de $106^{\circ} \mathrm{C}$, e detector tipo FID a $190^{\circ} \mathrm{C}$. O gás de arraste utilizado foi o nitrogênio, sem rampa de aquecimento. $\mathrm{O}$ padrão interno utilizado foi o ácido 2-metilbutírico, sendo acrescentados, em cada tubo para leitura em cromatógrafo, $100 \mu \mathrm{L}$ do padrão interno, $800 \mu \mathrm{L}$ da amostra e $200 \mu \mathrm{L}$ de ácido fórmico. Uma mistura de ácidos graxos voláteis com concentração conhecida foi utilizada como padrão externo para a calibração do integrador (Campos et al., 2004).

Os dados obtidos foram submetidos à análise de variância e regressão em nível de 5\% de probabilidade, utilizando-se o pacote estatístico SAS (Statistical ... [200-]).

\section{RESULTADOS E DISCUSSÃO}

Não houve efeito de interação tempo de coleta do líquido ruminal versus proporção de concentrado $(\mathrm{P}>0,05)$ sobre os AGV estudados. As médias apresentadas para os ácidos acético e propiônico foram de $57,7 \%$ e $23,7 \%$, respectivamente, dentro da faixa de normalidade apresentada por Berchielli et al. (2006), entre 54 e 74\%, para o 
ácido acético, e 16 e 27\%, para o ácido propiônico.

A maior concentração de ácido acético ocorreu com 46,2\% de concentrado, e não houve diferença significativa com relação às concentrações de ácido acético nos diferentes tempos de amostragem, em função da proporção de concentrado da dieta (Tab. 2). Ao trabalharem com polpa cítrica em substituição da silagem de milho, Nogueira et al. (2005) também não observaram efeito significativo na concentração de ácido acético, com obtenção de valores iguais a 67,$25 ; 66,22$ e $66,49 \mathrm{mM} / \mathrm{mL}$ para teores de 40 , 60 e $80 \%$ de polpa cítrica, respectivamente.
Para o ácido propiônico, a concentração máxima ocorreu com 8,78h após alimentação, com a dieta de $39,7 \%$ do concentrado. Nogueira et al. (2005), ao utilizarem diferentes teores de polpa cítrica em substituição ao milho na dieta de bovinos Nelore, observaram concentração máxima de ácido propiônico duas horas após a alimentação com dieta apenas de milho, atribuindo esse fato ao teor de amido na dieta, que proporcionou maior produção de propionato. No presente trabalho, apesar do aumento dos teores de concentrado, aparentemente não houve rápida degradação dos carboidratos, o que é indicado pelos valores altos de $\mathrm{pH}$ (Fig. 1), sugerindo um ambiente ruminal mais favorável para microrganismos celulolíticos.

Tabela 2. Médias da concentração $(\mathrm{mM} / \mathrm{mL})$ de ácidos acético e propiônico, e proporção acético:propiônico (C2:C3) no líquido ruminal de vacas alimentadas com diferentes teores de concentrado em função do tempo (h) pós-prandial

\begin{tabular}{|c|c|c|c|c|}
\hline \multirow{2}{*}{$\begin{array}{l}\text { Tempo } \\
\text { (horas) }\end{array}$} & \multicolumn{4}{|c|}{ Concentrado (\%) } \\
\hline & 30 & 40 & 50 & 60 \\
\hline & \multicolumn{4}{|c|}{ ácido acético $^{1}$} \\
\hline 0 & $45,42 \pm 7,89$ & $53,90 \pm 11,48$ & $46,03 \pm 7,78$ & $59,13 \pm 13,70$ \\
\hline 3 & $55,21 \pm 4,73$ & $73,38 \pm 6,49$ & $66,28 \pm 7,09$ & $51,31 \pm 11,76$ \\
\hline 6 & $43,43 \pm 12,08$ & $50,66 \pm 5,91$ & $64,31 \pm 5,42$ & $53,61 \pm 13,12$ \\
\hline 9 & $60,26 \pm 11,56$ & $52,07 \pm 1,99$ & $59,74 \pm 8,44$ & $44,27 \pm 5,78$ \\
\hline \multirow[t]{2}{*}{12} & $52,02 \pm 8,47$ & $55,81 \pm 4,50$ & $70,39 \pm 4,56$ & $55,18 \pm 18,96$ \\
\hline & \multicolumn{4}{|c|}{ ácido propiônico ${ }^{2}$} \\
\hline 0 & $10,46 \pm 1,82$ & $12,59 \pm 3,20$ & $10,64 \pm 1,72$ & $13,73 \pm 2,98$ \\
\hline 3 & $16,71 \pm 1,11$ & $19,41 \pm 0,76$ & $25,73 \pm 6,62$ & $21,63 \pm 10,27$ \\
\hline 6 & $20,48 \pm 7,73$ & $33,27 \pm 11,42$ & $23,39 \pm 4,94$ & $24,44 \pm 11,14$ \\
\hline 9 & $36,85 \pm 10,57$ & $33,52 \pm 12,78$ & $27,49 \pm 8,22$ & $29,16 \pm 11,31$ \\
\hline \multirow[t]{2}{*}{12} & $22,17 \pm 9,30$ & $34,01 \pm 8,43$ & $18,95 \pm 0,57$ & $22,42 \pm 8,75$ \\
\hline & \multicolumn{4}{|c|}{ proporção acético:propiônico $(\mathrm{C} 2: \mathrm{C} 3)^{3}$} \\
\hline 0 & $4,38 \pm 0,19$ & $4,72 \pm 0,60$ & $4,38 \pm 0,30$ & $4,21 \pm 0,28$ \\
\hline 3 & $3,30 \pm 0,16$ & $3,77 \pm 0,23$ & $3,09 \pm 0,67$ & $3,49 \pm 0,90$ \\
\hline 6 & $2,43 \pm 0,60$ & $2,32 \pm 0,78$ & $3,15 \pm 0,62$ & $3,09 \pm 0,75$ \\
\hline 9 & $2,28 \pm 0,83$ & $2,06 \pm 0,44$ & $2,63 \pm 0,57$ & $2,54 \pm 0,89$ \\
\hline 12 & $3,53 \pm 0,94$ & $2,10 \pm 0,63$ & $3,74 \pm 0,33$ & $2,87 \pm 0,75$ \\
\hline
\end{tabular}

$\mathrm{P}>0,05 ; \mathrm{r}^{2}=$ coeficiente de determinação; $\mathrm{t}=$ tempo; $\mathrm{n}=$ concentrado $(\%)$.

${ }^{1} \mathrm{Y}=-17,2847+3,35734 . \mathrm{n}-0,0363608 . \mathrm{n}^{2}\left(\mathrm{r}^{2}=0,79\right)$.

${ }^{2} \mathrm{Y}=-16,0349+1,10647 . \mathrm{n}-0,0104698 \cdot \mathrm{n}^{2}\left(\mathrm{r}^{2}=0,73\right)$.

${ }^{3} Y=4,60679-0,00664592 \cdot n+0,0000817878 \cdot n^{2}-0,0292886 t^{2}+0,000831072 . n . t\left(r^{2}=0,77\right)$.

A proporção acetato:propionato $(\mathrm{C} 2: \mathrm{C} 3)$ apresentou comportamento quadrático em função do tempo (Tab. 2), semelhante aos padrões apresentados por Teixeira e Teixeira (2001), que indicaram a proporção de $\mathrm{C} 2: \mathrm{C} 3$ ideal entre $2: 1 \mathrm{e}$ 4:1. Ao diminuírem a proporção de volumoso de $70 \%$ para $40 \%$ em dietas de vacas secas, Rodrigues et al. (2000) não observaram efeito significativo na proporção de $\mathrm{C} 2$ : $\mathrm{C} 3$, resultado confirmado no presente trabalho.

Resultados distintos foram verificados por Balieiro-Neto e Melloti (2007), que observaram efeito da queda na proporção acetato:propionato, com incremento nas porcentagens de ácido propiônico, ao usarem de 3 e $6 \%$ de gordura na dieta de bovinos e com $60 \%$ de volumoso, o que, 
provavelmente, favoreceu a lipólise, em função dos valores de $\mathrm{pH}$, contribuindo para presença de ácidos graxos livres no meio. Tal fato não poderia ter ocorrido neste experimento, uma vez que as médias de $\mathrm{pH}$ permaneceram acima de 6,2, considerado como condição mínima para melhoria da ação de bactérias fibrolíticas (Fig. 1).

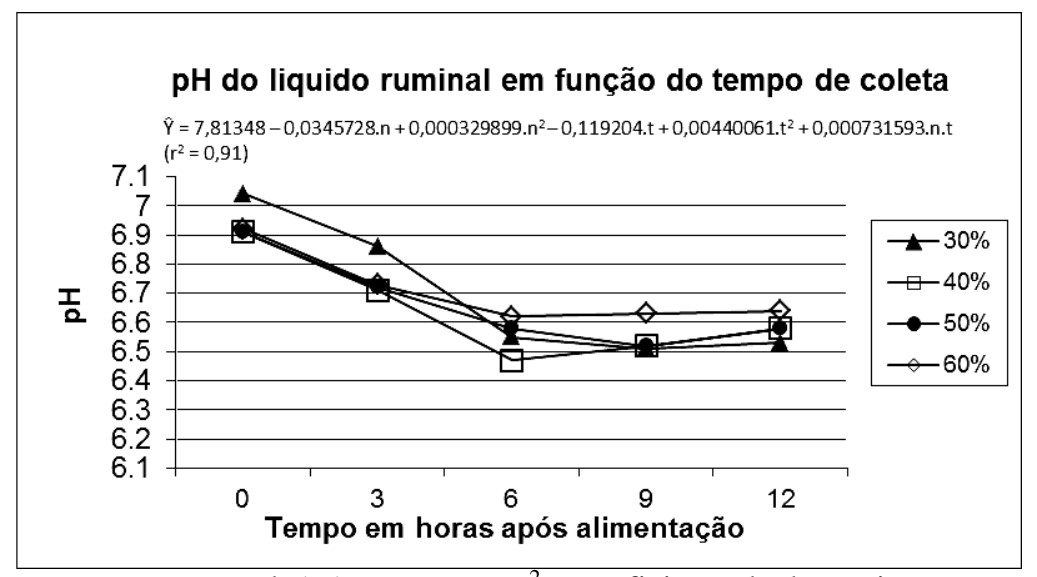

$\mathrm{n}=$ concentrado $(\%) ; \mathrm{t}=$ tempo; $\mathrm{r}^{2}=$ coeficiente de determinação

Figura 1. Variação do pH ruminal em função do tempo (h) após alimentação nas diferentes porcentagens de concentrado.

Não houve efeito significativo dos teores de concentrado sobre a concentração dos ácidos isobutírico, butírico, isovalérico e valérico (Tab. 3). As concentrações máximas ocorreram entre sete e oito horas após a alimentação, e com máximo de $47 \%$ de concentrado na dieta.

O uso de ureia nas dietas com 30, 40 e $50 \%$ de concentrado no presente experimento provavelmente favoreceu o aumento inicial da concentração de nitrogênio amoniacal (Fig. 2), que culminou com aumento da concentração de ácidos até teores de $50 \%$ do concentrado na dieta, e aparente diminuição com teores de $60 \%$. Reduções de ácido butírico têm sido relacionadas a altas porcentagens de concentrado, com o uso de diferentes fontes de gordura na dieta de bovinos, indicando queda no número ou na atividade de alguns microrganismos, em razão do efeito tóxico dos lipídios (Vargas et al., 2001; Eifert et al., 2005; Balieiro-Neto e Melotti, 2007).

A inclusão de ureia na dieta de ruminantes pode aumentar a população de microrganismos celulolíticos, e na presença de amido existe efeito estimulatório sobre tal população, que pode evitar a rápida fermentação a ácido lático, o que dificulta a diminuição do $\mathrm{pH}$ do líquido ruminal e promove estabilidade do processo fermentativo
(Nogueira Filho et al., 2001; Coalho et al., 2003), assim como aumento na concentração de nitrogênio amoniacal.

Concentrações ruminais de isovalerato e isobutirato são indicativos de fermentação de aminoácidos, os quais quando em altos teores, favorecem o acúmulo de tais AGVs, principal fator de redução do $\mathrm{pH}$ (Vargas et al., 2001), o que não foi observado no presente trabalho (Fig. 1). Christensen et al. (1994) verificaram tendência de redução de isovalerato em dietas suplementadas com óleo de milho e sebo bovino, sem efeito sobre o $\mathrm{pH}$ ruminal.

Bernardes et al. (2007), ao fornecerem caroço de algodão a bezerros, com 90 dias de idade, observaram $\mathrm{pH}$ ruminal semelhante ao de um animal adulto e demonstraram que o caroço de algodão foi capaz de manter o $\mathrm{pH}$ ruminal na faixa favorável ao crescimento de bactérias celulolíticas. Neste experimento, também não foi verificado efeito do teor de concentrado com relação ao $\mathrm{pH}$, que se manteve estável, com médias acima de 6,4 em todos os tratamentos (Fig. 1), indicando não haver acidificação do meio, mesmo na dieta com $60 \%$ de concentrado, estando dentro da faixa aceitável para máximo crescimento microbiano e máxima digestão de fibra, entre 6 e 7 (Hoover e Stokes, 1991). 


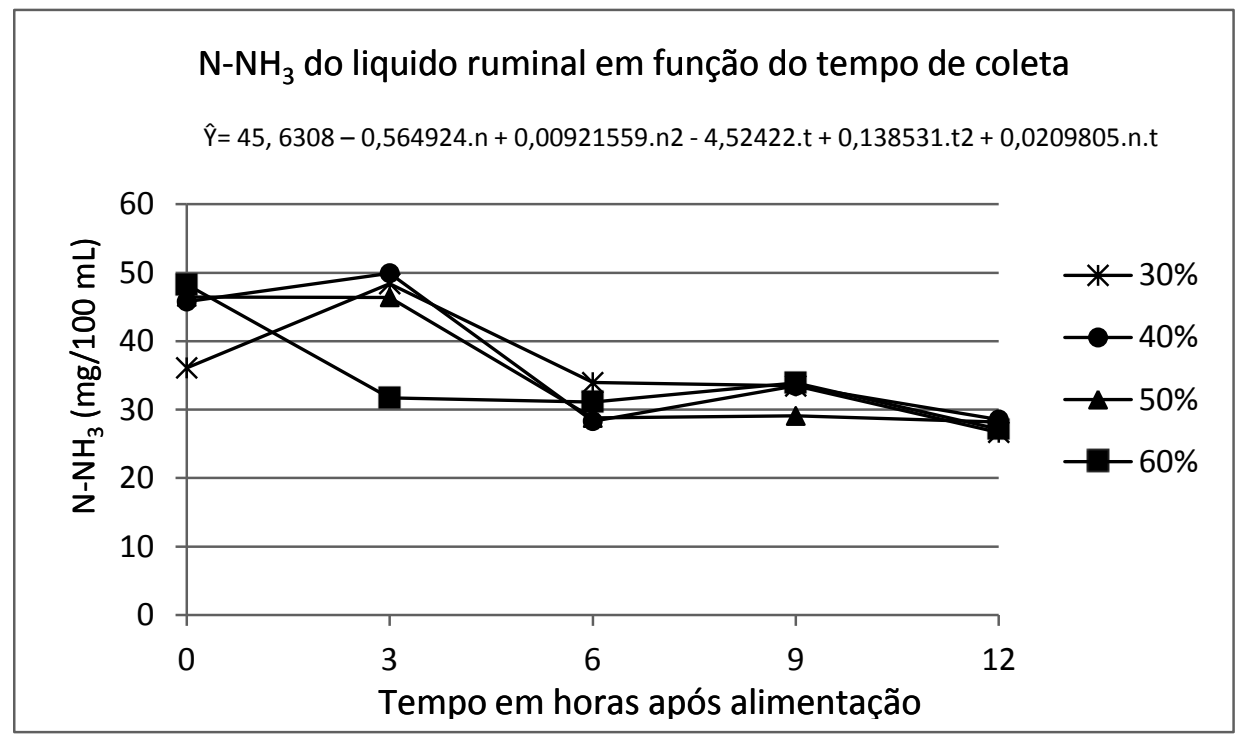

$\mathrm{n}=$ concentrado $(\%) ; \mathrm{t}=$ tempo; $\mathrm{r}^{2}=$ coeficiente de determinação

Figura 2. Variação do $\mathrm{N}-\mathrm{NH}_{3}$ ruminal $(\mathrm{mg} / 100 \mathrm{~mL})$ em função do tempo (h) após alimentação nos diferentes teores de concentrado.

Tabela 3. Médias das concentrações $(\mathrm{mM} / \mathrm{mL})$ dos ácidos isobutírico, butírico, isovalérico e valérico no líquido ruminal de vacas alimentadas com diferentes teores de concentrado em função do tempo (h) pósprandial

\begin{tabular}{|c|c|c|c|c|}
\hline \multirow{2}{*}{$\begin{array}{l}\text { Tempo } \\
\text { (horas) }\end{array}$} & \multicolumn{4}{|c|}{ Concentrado (\%) } \\
\hline & 30 & 40 & 50 & 60 \\
\hline & \multicolumn{4}{|c|}{ Isobutírico $^{1}$} \\
\hline 0 & $1,31 \pm 0,14$ & $1,53 \pm 0,41$ & $2,13 \pm 0,42$ & $1,50 \pm 0,41$ \\
\hline 3 & $1,17 \pm 0,04$ & $1,32 \pm 0,04$ & $1,37 \pm 0,12$ & $0,96 \pm 0,18$ \\
\hline 6 & $1,01 \pm 0,10$ & $0,86 \pm 0,09$ & $1,20 \pm 0,13$ & $0,97 \pm 0,19$ \\
\hline 9 & $0,92 \pm 0,17$ & $1,02 \pm 0,10$ & $1,46 \pm 0,40$ & $0,92 \pm 0,15$ \\
\hline \multirow[t]{2}{*}{12} & $0,80 \pm 0,09$ & $0,98 \pm 0,09$ & $1,27 \pm 0,02$ & $1,00 \pm 0,19$ \\
\hline & \multicolumn{4}{|c|}{ Butírico $^{2}$} \\
\hline 0 & $7,35 \pm 2,39$ & $12,46 \pm 3,23$ & $11,45 \pm 1,02$ & $12,56 \pm 2,88$ \\
\hline 3 & $10,80 \pm 0,83$ & $13,17 \pm 0,59$ & $14,93 \pm 1,11$ & $11,60 \pm 2,85$ \\
\hline 6 & $9,37 \pm 2,12$ & $12,46 \pm 1,87$ & $14,05 \pm 0,45$ & $11,97 \pm 2,51$ \\
\hline 9 & $18,82 \pm 7,26$ & $15,75 \pm 1,14$ & $15,05 \pm 1,74$ & $14,56 \pm 1,85$ \\
\hline \multirow[t]{2}{*}{12} & $8,44 \pm 1,73$ & $14,14 \pm 1,51$ & $13,12 \pm 0,73$ & $12,04 \pm 3,31$ \\
\hline & \multicolumn{4}{|c|}{ Isovalérico $^{3}$} \\
\hline 0 & $2,21 \pm 0,31$ & $2,58 \pm 0,59$ & $3,45 \pm 0,64$ & $2,65 \pm 0,70$ \\
\hline 3 & $2,05 \pm 0,13$ & $2,27 \pm 0,16$ & $2,64 \pm 0,38$ & $1,88 \pm 0,36$ \\
\hline 6 & $1,93 \pm 0,10$ & $1,87 \pm 0,05$ & $2,38 \pm 0,22$ & $1,90 \pm 0,17$ \\
\hline 9 & $2,03 \pm 0,30$ & $2,04 \pm 0,23$ & $2,70 \pm 0,70$ & $2,07 \pm 0,33$ \\
\hline \multirow[t]{2}{*}{12} & $1,48 \pm 0,18$ & $2,02 \pm 0,14$ & $2,15 \pm 0,07$ & $1,85 \pm 0,34$ \\
\hline & \multicolumn{4}{|c|}{ Valérico ${ }^{4}$} \\
\hline 0 & $1,14 \pm 0,14$ & $1,34 \pm 0,32$ & $1,32 \pm 0,34$ & $1,78 \pm 0,43$ \\
\hline 3 & $1,84 \pm 0,20$ & $1,94 \pm 0,08$ & $2,31 \pm 0,14$ & $1,68 \pm 0,40$ \\
\hline 6 & $1,48 \pm 0,37$ & $1,95 \pm 0,26$ & $2,24 \pm 0,19$ & $1,53 \pm 0,34$ \\
\hline 9 & $1,94 \pm 0,17$ & $2,02 \pm 0,06$ & $2,86 \pm 0,79$ & $1,74 \pm 0,46$ \\
\hline 12 & $1,31 \pm 0,34$ & $1,84 \pm 0,10$ & $1,90 \pm 0,15$ & $1,58 \pm 0,40$ \\
\hline
\end{tabular}

$\mathrm{P}>0,05 ; \mathrm{r}^{2}=$ coeficiente de determinação; $\mathrm{t}=$ tempo; $\mathrm{n}=$ concentrado $(\%)$.

${ }^{1} \mathrm{Y}=-1,00474+0,119081 . \mathrm{n}-0,00128594 . \mathrm{n}^{2}-0,142467 \mathrm{t}+0,00758457 \cdot \mathrm{t}^{2}+0,000155301 . n \cdot \mathrm{t}\left(\mathrm{r}^{2}=0,72\right)$.

${ }^{2} Y=-12,1352+0,962412 . n-0,00954294 . n^{2}+1,23786 t-0,0540539 \cdot t^{2}-0,00911044 . n \cdot t\left(r^{2}=0,41\right)$.

${ }^{3} \mathrm{Y}=-1,68797+0,193017 \cdot \mathrm{n}-0,00202219 \cdot \mathrm{n}^{2}-0,111412 \cdot \mathrm{t}+0,00579589 \cdot \mathrm{t}^{2}-0,000325235 \cdot \mathrm{n} \cdot \mathrm{t}\left(\mathrm{r}^{2}=0,66\right)$.

${ }^{4} Y=-2,53924+0,175967 . n-0,00184199 . n^{2}+0,199366 . t-0,012469 . t^{2}-0,000574218 . n . t\left(r^{2}=0,57\right)$. 
Os AGV totais apresentaram média geral de 96,36 mM/mL (Tab. 4), com concentração máxima em 8,40 horas após alimentação e 45\% de concentrado na dieta, aproximadamente. A não observação de alterações com aumento do teor de concentrado indica que o volumoso utilizado (silagem de milho) foi de excelente qualidade, sendo fundamental na manutenção das condições ruminais. Ítavo et al. (2000) observaram comportamento quadrático em função do tempo nos resultados de $\mathrm{AGV}$, no líquido ruminal de ovinos submetidos ao bagaço de laranja na dieta. Segundo Cameron et al. (1991), a concentração total ou proporções de AGV no fluido ruminal não são modificadas em situações nas quais a digestibilidade dos nutrientes não é influenciada pelas dietas.
Ao utilizarem óleo de soja em combinação com monensina em dietas de vacas lactantes, Eifert et al. (2005) também não observaram influência nos AGV totais, com média de $99,43 \mathrm{mM} / \mathrm{mL}$. Resultados similares ao desta pesquisa (Tab. 4) já haviam sido obtidos por Chapaval et al. (2008), que, ao analisarem diferentes proporções de volumoso e concentrado, não observaram efeito da proporção de concentrado na dieta sobre a soma dos AGV dosados. O uso de lipídios saturados e insaturados tem demonstrado pequenos ou insignificantes efeitos sobre os parâmetros ruminais (Palmquist et al., 1993; Valinote et al., 2006), o que sugere que a gordura usada nas dietas tenha estimulado a atividade microbiana ruminal, sem alteração na produção total de ácidos graxos voláteis.

Tabela 4. Médias das concentrações $(\mathrm{mM} / \mathrm{mL})$ dos $\mathrm{AGV}$ totais no líquido ruminal de vacas alimentadas com diferentes teores de concentrado em função do tempo (h) pós-prandial

\begin{tabular}{|c|c|c|c|c|}
\hline \multirow{2}{*}{$\begin{array}{l}\text { Tempo } \\
\text { (horas) }\end{array}$} & \multicolumn{4}{|c|}{ Concentrado (\%) } \\
\hline & 30 & 40 & 50 & 60 \\
\hline 0 & $67,89 \pm 11,13$ & $84,41 \pm 18,82$ & $75,02 \pm 9,74$ & $91,35 \pm 20,91$ \\
\hline 3 & $87,78 \pm 6,69$ & $111,49 \pm 6,75$ & $113,27 \pm 7,06$ & $89,07 \pm 19,92$ \\
\hline 6 & $77,70 \pm 19,35$ & $101,05 \pm 15,40$ & $107,56 \pm 4,09$ & $94,43 \pm 22,21$ \\
\hline 9 & $120,81 \pm 15,71$ & $106,42 \pm 13,55$ & $109,29 \pm 13,08$ & $92,73 \pm 16,86$ \\
\hline 12 & $86,23 \pm 15,36$ & $108,80 \pm 5,37$ & $107,78 \pm 4,41$ & $94,07 \pm 26,80$ \\
\hline
\end{tabular}

$\mathrm{P}>0,05 ; \mathrm{r}^{2}=$ coeficiente de determinação; $\mathrm{t}=$ tempo; $\mathrm{n}=$ concentrado $(\%)$.

$\mathrm{Y}=-56,0612+5,99406 \cdot \mathrm{n}-0,0615236 . \mathrm{n}^{2}+7,83304 \cdot \mathrm{t}-0,319962 \cdot \mathrm{t}^{2}\left(\mathrm{r}^{2}=0,58\right)$.

As concentrações máximas de AGV total ocorreram por volta de oito horas após alimentação, coincidindo com valores mínimos de $\mathrm{pH}$ e $\mathrm{N}-\mathrm{NH}_{3}$ (Fig. 1 e 2), entre seis e oito horas. Valores máximos de AGV obtidos por Ítavo et al. (2000) ocorreram três horas após alimentação, concomitantemente com valores mínimos de $\mathrm{pH}$, devido à relação inversamente proporcional, o que também foi observado no presente trabalho.

\section{CONCLUSÃO}

Os diferentes teores de concentrado na dieta não interferiram na concentração de ácidos graxos voláteis no líquido ruminal de vacas, assim podem-se utilizar dietas com até $60 \%$ de concentrado sem alterações nos parâmetros ruminais.

\section{REFERÊNCIAS BIBLIOGRÁFICAS}

BALIEIRO-NETO, G.; MELLOTI, L. Produção de ácidos graxos voláteis e contagem de protozoários ruminais em bovinos suplementados com gordura. Braz. J. Vet. Res. Anim. Sci., v. 44, p. 115-121, 2007.

BARKER, I.K.; VAN DREUMEL, A.A.; PALME, N. The alimentary system. In: JUBB, K.V.F.; KENNEDY, P.C.; PALMER, N. Pathology of domestic animals. 4.ed. San Diego: Academic, 1995. $574 \mathrm{p}$.

BERCHIELLI, T.T.; PIRES, A.V.; OLIVEIRA, S.G. Nutrição de ruminantes. Jaboticabal: Funep, 2006. v.2, 583p.

BERGMAN, E.N. Energy contributions of volatile fatty acids from the gastrointestinal tract in various species. Physiol. Rev., v.10, p.567-589, 1990.

BERNARDES, E.B.; COELHO, S.G.; CARVALHO, A.U. et al. Efeito da substituição do feno de Tifton 85 pelo caroço de algodão como fonte de fibra na dieta de bezerros. Arq. Bras. Med. Vet. Zootec., v.59, p.955964, 2007. 
CAMPOS, F.P.; NUSSIO, C.M.B.; NUSSIO, L.G. Métodos de análises de alimentos. Piracicaba: FEALQ, 2004. 135 p.

CAMERON, M.R.; KLUSMEYER, T.H.; LYNCH, G.L. et al. Effects of urea and starch on rumen fermentation, nutrient passage to the duodenum and performance of cows. J. Dairy Sci., v.74, p.1321-1336, 1991.

CHAPAVAL, L.; MELOTTI, L.; ROSSI JÚNIOR, P. et al. Relação volumoso concentrado sobre as concentrações ruminais de amônia, $\mathrm{pH}$ e ácidos graxos voláteis em vacas leiteiras mestiças. Rev. Bras. Saúde Prod. Anim., v.9, p.18-28, 2008.

CHRISTENSEN, R.A.; CAMERON, M.R.; CLARK, J.H. et al. Effects of amount of protein and ruminally protected amino acids in the diet of dairy cows fed supplemental fat. J. Dairy Sci., v.77, p.1618-1629, 1994.

COALHO, M.R.; NOGUEIRA FILHO, J.C.M.; CUNHA, J.A. et al. Estudo dos protozoários ciliados em bovinos consumindo dietas com diferentes níveis de proteína não degradável no rúmen. Acta Scient. Anim. Sci., v.25, p.193-199, 2003.

COSTA, S.F.; PEREIRA, M.N.; MELO; L.Q. et al. Alterações morfológicas induzidas por butirato, propionato e lactato sobre a mucosa ruminal e epiderme de bezerros. II. Aspectos ultraestruturais. Arq. Bras. Med. Vet. Zootec., v.60, p.10-18, 2008.

EIFERT, E.C.; LANA, R.P.; LEÃO, M.I. et al. Efeito da combinação de óleo de soja e monensina na dieta sobre o consumo de matéria seca e a digestão em vacas lactantes. Rev. Bras. Zootec., v.34, p.297-308, 2005.

HOOVER, W.H.; STOKES, S.R. Balancing carbohydrates and proteins for optimum rumen microbial yield. J. Dairy Sci., v.74, p.3630-3644, 1991.

ÍTAVO, L.C.V.; SANTOS, G.T.; JOBIM, C.C. et al. Avaliação da silagem de bagaço de laranja com diferentes aditivos por intermédio dos parâmetros de fermentação ruminal de ovinos e contribuição energética dos ácidos graxos voláteis. Rev. Bras. Zootec., v.29, p.1491-1497, 2000.

ÍTAVO, C.C.B.F.; ÍTAVO, L.C.V.; SILVA, F.F. Aspectos da fermentação ruminal de lipídios. In: ÍTAVO, L.C.V.; ITAVO, C.C.B.F (Org.). Nutrição de ruminantes: aspectos relacionados à digestibilidade $\mathrm{e}$ aproveitamento de nutrientes. Campo Grande: UCDB, 2005. p.151-166.

IVAN, M.; MIR, P.S.; KOENNG, K.M. et al. Effects of dietary sunflower seed oil on rumen protozoa population and tissue concentration of conjugated linolenic acid in sheep. Small Ruminant Res., v. 41, p. 215-227, 2001.
JENKINS, T.C. Symposium: advances in ruminant lipid metabolism - lipid metabolism in the rumen. $J$. Dairy Sci., v.76, p.3851-3863, 1993.

NAGARAJA, T.G.; NEWBOLD, C.J.; Van NEVEL, C.J. et al. Manipulation of ruminal fermentation. In: HOBSON, P.N.; STEWART, C.S. (Eds.). The rumen microbial ecosystem. 2.ed. London: Blackie Academic \& Professional, 1997. p.523-632.

NOGUEIRA FILHO, J.C.M.; MARTIN-ORÚE, S.M.; BALCELLS, J. et al. Níveis de proteína degradável para novilhas em crescimento sobre a concentração de protozoários ciliados e outros parâmetros ruminais. Acta Scient., v. 23, p. 945-951, 2001.

NOGUEIRA, K.A.; NOGUEIRA FILHO, J.C.M.; LEME, P.R. et al. Substituição do milho pela polpa de citros sobre a fermentação ruminal e protozoários ciliados. Acta Scient. Anim. Sci., v. 27, p. 123-127, 2005.

ØRSKOV, E. R.; RYLE, M. Energy nutrition in ruminants. [s.1.]:Elsevier Applied Science, 1990. 149p.

PALMQUIST, D.L.; WEISBJERG, M.R.; HVELPLUND, T. Ruminal, intestinal and total digestibility of nutrients in cows fed diets high in fat and undegradable protein. J. Dairy Sci., v.76, p.13531364, 1993.

RODRIGUES, P.H.M.; LUCCI, C.S.; CASTRO, A.L. Efeitos da lasalocida sódica e proporção volumoso/concentrado sobre a fermentação ruminal em vacas secas. Braz. J. Vet. Res. Anim. Sci., v.37, p. 434-443, 2000.

SILVA, D.J.; QUEIROZ, A.C. Análises de alimentos: métodos químicos e biológicos. 3.ed. Viçosa: UFV, 2002. 235p.

STATISTICAL analysis system: user's guide - SAS. Release 9.1. cary, NC:SAS Institute, [200-].

TAMMINGA, S.; VAN VUUREN, M. Formation and utilization of end products of lignocelluloses degradation in ruminants. Anim. Feed Sci. Tech., v.21, p.141-159, 1988.

TEIXEIRA, J.C.; TEIXEIRA, L.F.A.C. Princípios de nutrição de bovinos leiteiros. Lavras: UFLA/FAEP, 2001. 245p. (Textos acadêmicos).

VALINOTE, A.C.; NOGUEIRA FILHO, J.C.M.; LEME, P.R. et al. Fontes de lipídio e monensina sódica na fermentação, cinética e degradabilidade ruminal de bovinos. Pesqui. Agropecu. Bras., v.41, p.117-124, 2006.

VARGAS, L.H.; LANA, R.P.; MÂNCIO, A.B. et al. Influência de Rumensin®, óleo de soja e níveis de concentrado sobre o consumo e os parâmetros fermentativos ruminais em bovinos. Rev. Bras. Zootec., v. 30, p.1650-1658, 2001. 